\title{
Explicit Simulations of Convective-Scale Transport of Mineral Dust in Severe Convective Weather
}

\author{
Tetsuya TAKEMI
}

Department of Environmental Science and Technology, Tokyo Institute of Technology, Yokohama, Japan

(Manuscript received 13 July 2004, in final form 20 January 2005)

\begin{abstract}
Convective-scale transport of mineral dust in a severe weather setting is investigated with the approach of three-dimensional cloud-resolving simulations coupled with a dust emission-transport modeling. The simulations are intended to explicitly represent convective- and cloud-scale processes (such as updraft/downdraft, surface cold pool, precipitation) in a squall-line-type convective system, and are performed in an idealized setup in order to focus the primary mechanisms for convective-scale transport of dust within a squall-line system. Initialized based on an observation in a severe duststorm case over the Gobi Desert in China, the cloud model well simulates an observational feature of the squall line and the associated duststorm in spite of a simplified model setup.

Dust is emitted by strong surface winds associated with a well-developed surface cold pool, and is contained and mixed within the cold pool: a high dust concentration of greater than $10 \mathrm{mg} \mathrm{m}^{-3}$ is induced. Owing to a high subgrid-turbulence mixing at the leading edge of the cold pool, the contained dust is transferred out of the cold pool and is entrained into the updraft region at the cold pool edge. Dust is then transported upward by the convective updraft which is continuously regenerated at the cold-pool leading edge, and spreads laterally in the cross-line directions at upper levels by system-scale circulation. Rearward dust transport relative to the leading edge of the system is pronounced at upper levels, according to the prevalent front-to-rear flow typically found in the squall-line systems. This study suggests that the representations of convective-scale transport processes should be adequately updated in order to improve the accuracy of the regional-scale to global-scale numerical predictions.
\end{abstract}

\section{Introduction}

Mineral dust produced by surface wind erosion and its transport in the atmosphere has a significant influence on the weather and climate, not only in regional scale but also in global scale, by affecting radiative transfer, cloud microphysical processes, atmospheric chemical processes, and so forth. Primarily, the origin of such mineral dust is distributed in the

Corresponding author address: Dr. Tetsuya Takemi, Department of Environmental Science and Technology, Tokyo Institute of Technology, G5-7, 4259 Nagatsuta, Yokohama, Kanagawa 2268502, Japan.

E-mail: takemi@depe.titech.ac.jp

(C) 2005, Meteorological Society of Japan arid and semiarid regions of the Earth, and among the source regions of mineral dust, the Asian Continent has been recognized as the most vast and important area (Seinfeld et al. 2004). A huge area of desert extends over the continent from the Middle East to Central Asia and further to East Asia.

In the arid regions of East Asia, specifically the Taklamakan Desert in the northwest of China and the Gobi Desert over northern China and Mongolia, mineral dust emission and transport frequently occur in spring (Parungo et al. 1994) due to a high activity of midlatitude cyclones (Chen et al. 1991; Qian et al. 2002). Takemi and Seino (2005a, b) investigated the relationship between dust weather 
occurrence and cyclone activity as well as mesoscale cloud systems from a statistical point of view and found that in the Gobi Desert the frontal activity and the embedded mesoscale cloud systems have a close tie with the dust occurrence while in the Taklamakan Desert that connection is relatively weak. With the development of an intense cyclone or a wellorganized mesoscale cloud system, disastrous duststorms and dust weathers may occur over the Gobi region and over eastern China, Korea, and Japan as well. As a case study, Takemi (1999b) and Takemi and Satomura (2000) examined the structure and dynamics of the mesoscale convective cloud system that spawned a severe duststorm over the Gobi Desert on 5 May 1993, and showed that the duststorm was caused by a vigorous cold surface outflow which emanated from the mesoscale system. This cold outflow advanced over the region, associating with a striking dust front (Mitsuta et al. 1995). Other major dust outbreaks were investigated for the cases in April 2001 during the international field experiment ACE-Asia (the Asian Pacific Regional Aerosol Characterization Experiment) (Seinfeld et al. 2004, and the references therein), and the dust events examined were associated with intense cyclone activities. Thus it can be said that strong cyclone activity, including embedded mesoscale convective systems, is the main cause of severe duststorms, which serve as a significant source of mineral dust transport in the atmosphere.

Meanwhile, numerical modeling studies play a crucial role in evaluating and forecasting the amount of dust emission and transport. Physical models for dust emission processes at the ground are described in detail in Shao (2000), and there are a number of numerical studies that deal with the transport of mineral dust by implementing a certain type of dust emission model (e.g., Liu and Westphal 2001; Shao et al. 2002; In and Park 2002; Gong et al. 2003; Uno et al. 2003). A synoptic-scale feature of the long-range transport of aeolian dust has been successfully simulated by these studies, and ongoing efforts have been made in order to improve the accuracy of the simulations by comparing the simulated results with in-situ observations and by performing sensitivity experiments such as on grid-size dependency and dust-emission scheme.
One of the critical issues for the better representation of long-range transport of dust is the modeling of vertical transport processes of dust from the surface to the free troposphere, because it directly controls the amount of dust transported vertically from the surface to the upper atmosphere. Owing to coarse horizontal resolutions (at a couple of tens of kilometer), the previous simulations were not able to explicitly represent the vertical transport processes from a perspective in a mesoscale or smaller, or the mechanisms for the vertical transport of dust were not addressed and clarified. Liu et al. (2003) conducted numerical simulations of dust transport during the development of a synoptic-scale cyclone over East Asia at a horizontal resolution of $27 \mathrm{~km}$ that is higher than those in the previous studies. They concluded that the mechanical and convective turbulence plays a major role in mixing dust from the surface to the boundary-layer top and the vertical advection that is assumed to be cold frontal ascent contributes to the vertical transport to higher altitudes. In spite of their high-resolution simulations, however, convective-scale processes such as updraft/ downdraft and gust front were not explicitly resolved; the dynamical role of these convective-scale processes on the vertical transport of dust was not still addressed. With an increasing development of computer resources, simulations with much higher resolutions, namely, cloud-resolving simulations, in realistic environments in a regional-scale as well as in a global-scale may be affordable in the foreseeable future, and the convective processes relevant to dust transport will be revealed. Toward this goal, a study that deals with the dynamics of convective-scale dust transport by explicitly resolving cloud-scale processes is required in order to present a conceptual model for the vertical transport processes of dust in a convective-scale perspective.

In the present study, we will investigate numerically the dynamical roles of convectivescale updrafts and downdrafts as well as mesoscale circulations within mesoscale convective systems on the three-dimensional (3D) transport of mineral dust by explicitly representing convective motions and cloud and precipitation development. We assume that the mesoscale convective systems are those that develop 
in the frontal regions of mid-latitude cyclones. By implementing a standard dust-emission scheme, 3D cloud-resolving simulations of a squall-line-type convective system and the associated duststorm are performed without the help of cumulus and/or boundary-layer mixing parameterizations. Dynamics that determine and control the convective-scale transport of dust is described, and thereby the dynamical processes of dust transport in a convective-scale as well as in a mesoscale are demonstrated. This study is, to our knowledge, the first attempt to examine the convective-scale dust transport with a cloud-resolving modeling approach, and is intended to present a conceptual view for the convective-scale transport of dust. The case of the 5 May 1993 severe duststorm is examined here, since the basic mechanisms for the relevant mesoscale convective system (i.e., squall line) were thoroughly described by Takemi and Satomura (2000). In order to focus the basic aspects of the mechanisms of convective transport processes, numerical experiments have been conducted in idealized setups.

\section{Model setup and experimental design}

\subsection{Cloud model setup}

The numerical model used in the present study is a non-hydrostatic cloud model, the Advanced Regional Prediction System (ARPS, Xue et al. 2000, 2001). This cloud model is designed for the explicit representation and simulations of convective clouds and storms, and therefore, the simulations with the ARPS model are appropriate for the purpose of the present study. Although the model can be used in a variety of setups, this study is intended to examine the basic dynamics of convective dust transport, and therefore the model is run in as simple a condition as possible: that is, all the simulations are performed in a 3D framework with a horizontally homogeneous base state. We neglect the Coriolis effect in the governing equations and the effects of radiative energy transfer as well. This setting is justified by the philosophy of Rotunno et al. (1988), Weisman and Rotunno (2004), Fovell and Tan (1998), and others who concentrate on the dynamical aspects of squall-line convective systems.

Cloud microphysical processes are parameterized with a scheme of Lin et al. (1983) which predicts the mixing ratios of water substance divided into six categories, namely water vapor $q_{v}$, cloud water $q_{c}$, rain water $q_{r}$, cloud ice $q_{i}$, snow $q_{s}$, and hail $q_{h}$. Subgrid-scale turbulence mixing is determined by the parameterization described in Klemp and Wilhelmson (1978) and Deardorff (1980), which uses a prognostic equation of turbulent kinetic energy in determining the mixing coefficients. We set different turbulence length-scales in the horizontal and vertical directions, taking into account the large difference of the horizontal and vertical grid spacings which will be described shortly. In the present simulations, the basestate boundary layer is in a convectively mixed condition, as described in Section 2.3, and hence the mixing length-scale in the boundary layer is defined by the method of Sun and Chang (1986). Surface momentum, heat, and moisture fluxes are calculated from stabilitydependent surface drag coefficients determined by the formulations of Businger et al. (1971), and the surface friction velocity $u_{*}$ is also derived from their formulations. For the flux calculations, the surface potential temperature is set at $315 \mathrm{~K}$, and the surface moisture content is set to zero.

The computational domain is $650 \mathrm{~km}$ in the $x$ (east-west) direction and $120 \mathrm{~km}$ in the $y$ (north-south) direction, extending from the surface to a height of $18.4 \mathrm{~km}$. The base-state surface pressure is fixed at $850 \mathrm{hPa}$ to conform to the situation of the 5 May 1993 Gobi duststorm. The heights hereinafter are referred to as those above the surface level. The horizontal grid resolution is $2 \mathrm{~km}$, which is sufficient to describe the convective and mesoscale nature of squall-line-type cloud systems (Weisman et al. 1997), while the vertical grid size is stretched from $20 \mathrm{~m}$ (at the lowest level) up to $810 \mathrm{~m}$ (at the model top). Since squall-line systems that align in the $y$ direction are simulated in our study, open lateral boundary conditions, a type presented in Durran and Klemp (1983), are specified at the $x$ boundaries, and periodic conditions at the $y$ boundaries. The top boundary is rigid lid with a Rayleigh-type damping layer above the $12-\mathrm{km}$ level to minimize wave reflections at the top boundary.

The model is integrated in time with a leapfrog method with the time step of $12 \mathrm{~s}$. The advection terms for all the prognostic variables are discretized with a fourth-order centered 
scheme for the horizontal terms and a secondorder scheme for the vertical. In order to suppress the unwanted development of small-scale noise, a fourth-order numerical mixing with the dissipation rate of $0.25 \times 10^{-3} \mathrm{~s}^{-1}$ is added only in the horizontal directions.

\subsection{Dust emission and transport modeling}

A mineral dust emission and transport module is implemented in ARPS, and is updated at each time step of ARPS. The prognostic equation of dust mixing ratio $q_{d}\left(\mathrm{~kg} \mathrm{~kg}^{-1}\right)$ is formulated as follows:

$$
\begin{aligned}
\frac{\partial}{\partial t}\left(\rho q_{d}\right)= & F_{\text {adv }}+F_{\text {mix }}+F_{f l u x} \\
& +F_{\text {grav }}+F_{\text {wet }}+F_{\text {revap }},
\end{aligned}
$$

where $\rho$ is the density of air, and $F_{a d v}, F_{\text {mix }}$, $F_{\text {flux }}, F_{\text {grav }}, F_{\text {wet }}$, and $F_{\text {revap }}$ are the terms representing advection, subgrid-turbulence mixing, surface emission flux, gravitational settling, wet scavenging, and re-production due to evaporation of rain water, respectively. The modeling of each term is described subsequently.

The vertical dust flux at the surface $F_{f l u x}$ $\left(\mathrm{kg} \mathrm{m}^{-2} \mathrm{~s}^{-1}\right)$ can be computed by an equation which defines the flux to be proportional to the fourth power of the surface friction velocity. This equation was derived by Westphal et al. (1988), Gillette and Passi (1988), and Nickling and Gillies (1993), and has been widely used in many modeling studies such as Liu and Westphal (2001), Uno et al. (2003), and others. The vertical dust flux in our simulations is calculated by the following equation in Liu and Westphal (2001):

$$
F_{f l u x}=C u_{*}^{4} \quad \text { if } u_{*} \geq u_{* t},
$$

where $C$ is a constant equal to $1.42 \times 10^{-5}$, and $u_{* t}$ is threshold friction velocity. This equation is adopted here for its simple form, which enables us to simplify the interpretation of the simulated results. In Liu and Westphal (2001) a parameter indicating a dust erodible fraction within each grid box is also included in (2); however, this study assumes that the surface is all dust erodible, and hence the fraction is set to one. In other words, we assume that dust could be emitted everywhere at the horizontally uniform surface according to (2), provided that the friction velocity exceeds the threshold value. We set the threshold as a constant: $u_{* t}=0.6 \mathrm{~m} \mathrm{~s}^{-1}$, following Liu and Westphal (2001) who chose this value to best represent the Mongolian and Chinese deserts. This assumption is plausible, since this study deals with a Chinese duststorm and does not take into account the horizontal variability of the surface characteristics.

In addition to the formulation of the surface dust flux, the size distribution of dust particle is another key factor controlling the dust mobilization and vertical flux, and modeling studies such as Takemura et al. (2000) and Uno et al. (2003) used the shape of the size distribution suggested from the observations over the Sahara by d'Almeida and Schutz (1983). In contrast, Liu and Westphal (2001) did not incorporate explicitly the dust-size dependency in their modeling study in order to focus the investigation of the dependence of dust production on grid resolution, and Uno et al. (2001) successfully simulated the basic structure of dust weather with a single-distributed dust model. The primary purpose of our study is to examine the basic dynamical processes regarding the convective-scale transport of dust in an idealized condition, and thus, we assume that the dust size is mono-distributed. Two sizes of the dust particle radius are examined here: $1.0 \mu \mathrm{m}$ and $10.0 \mu \mathrm{m}$, in order to represent small and large particle sizes.

The gravitational settling is modeled in the same manner with that found in Takemura et al. (2000) and Uno et al. (2003), and its velocity $v_{d}$ is given as follows:

$$
v_{d}=\frac{2 \rho_{d} r_{d}^{2} g}{9 \eta}
$$

where $\rho_{d}$ is the density of mineral dust $\left(=2.52 \times 10^{3} \mathrm{~kg} \mathrm{~m}^{-3}\right), r_{d}$ the radius of the dust particle, $g$ the acceleration of gravity $\left(=9.8 \mathrm{~m} \mathrm{~s}^{-2}\right)$, and $\eta$ the viscosity of air $\left(=1.78 \times 10^{-5} \mathrm{~kg} \mathrm{~m}^{-1} \mathrm{~s}^{-1}\right)$. In this formulation we set the radius of the dust particle to a size assumed to be examined.

Most of the dust modeling studies incorporate a dust scavenging process by cloud droplets and/or raindrops. This process is parameterized by relating the scavenging rate with rainfall intensity. In this study the rainfall intensity can be calculated from the fallout of rain-water content $\left(q_{r}\right)$ represented in the explicit cloud-microphysics parameterization. 
With the calculated rainfall intensity $R$ $\left(\mathrm{mm} \mathrm{h}^{-1}\right)$, the scavenging rate $\Lambda$ (in units of $\mathrm{s}^{-1}$ ) is diagnosed from the relationship given by Westphal et al. (1988):

$$
\Lambda=3.458 \times 10^{-4} R^{0.79} .
$$

Since $R$ can be derived from $q_{r}$, there is no distinction between in-cloud and below-cloud scavenging. Wet scavenging is applied when the rain intensity exceeds $0.1 \mathrm{~mm} \mathrm{~h}^{-1}$.

As dust is captured by rain water, the behavior of the rain-wet dust is predicted by another prognostic equation for the mixing ratio of wet dust $q_{d w}\left(\mathrm{~kg} \mathrm{~kg}^{-1}\right)$ :

$$
\frac{\partial}{\partial t}\left(\rho q_{d w}\right)=F_{a d v}^{\prime}+F_{m i x}^{\prime}+F_{f a l l}-F_{w e t}-F_{\text {revap }},
$$

where $F_{a d v}^{\prime}, F_{m i x}^{\prime}, F_{f a l l}, F_{\text {wet }}$, and $F_{\text {revap }}$ are the terms which represent advection, subgrid mixing, fallout, production due to wet scavenging, and depletion due to evaporation of rain water. The fall speed of the wet dust is set equal to that of the rain water, and is given by the cloud-microphysics scheme of Lin et al. (1983). We allowed the evaporation of rain that captures dust and its resulting re-production of dust from rain-wet dust, because it was demonstrated in the simple one-dimensional computations of Takemi (1999a) that a significant amount of rain evaporates below the cloud base owing to the very dry, deep boundary layer. The rate of the re-production of dust due to rain evaporation is computed by the rainevaporation equation defined in the cloudmicrophysics scheme.

The coefficient for the mixing term $F_{m i x}$ is assumed to be the same with that of the other scalar variables calculated by the ARPS subgrid-turbulence parameterization.

The time-integration and the advection differencing schemes in (1) and (5) are the same with those for the other prognostic variables in the ARPS, and the fourth-order numerical mixing is also added in the two equations.

\subsection{Experimental design}

A mesoscale convective system (i.e., a squall line in the present case) was at first reproduced by the cloud model without calculating the dust emission and transport, and then the reproduced squall line in a well-developed state was used for initializing the cloud model with the dust emission-transport calculations being performed this time.

In order to produce a squall line in the preliminary run, we placed around the lower center of the computational domain a $y$-oriented line thermal having a maximum potential temperature excess of $3 \mathrm{~K}$ with small random perturbations added (similar to Rotunno et al. 1988). The $x-z$ cross section of this thermal has a half-elliptic shape with its center placed at the surface, and the size is $20-\mathrm{km}$ radius in the $x$ direction and $4 \mathrm{~km}$ in the $z$ direction. The random perturbations are intended to allow 3D features of squall lines to develop.

Figure 1 shows the base-state vertical profiles of the thermodynamic variables and horizontal wind, which are determined from the observations over the Gobi Desert on 5 May 1993 and are similar to those used by Takemi and Satomura (2000). In the present simulations, the top of the mixed boundary layer is set at $3600 \mathrm{~m}$, with the moisture content in the mixed layer linearly decreasing with height. This moisture profile leads to an extremely dry condition at low levels; relative humidity near the surface is as low as $10 \%$. The dry condition results in a low convective available potential energy (so called CAPE) of $349 \mathrm{~J} \mathrm{~kg}^{-1}$ and a high lifting condensation level (LCL) of $4093 \mathrm{~m}$ for a surface air parcel. The horizontal winds considered here have only the $x$ component in order to simplify the experimental setups as much as possible and at the same time to sufficiently represent the squall-line structure and evolution.

The computational domain is translated at a constant speed in order to keep the interested convective disturbances stay around the central locations in the $x$ direction. By trial and error, this constant speed was chosen to be $20 \mathrm{~m} \mathrm{~s}^{-1}$. It is noted that in calculating the surface flux, no domain translation is performed at the surface level.

With these setups the cloud model without the dust model calculations was integrated up to $6 \mathrm{~h}$. Figure 2 shows the time evolution of some parameters, and it is demonstrated that the simulated cloud system acquired a welldeveloped stage in its evolution; all the parameters shown here vary around some constant values after 4 h. In Figs. 3 and 4 respectively, 

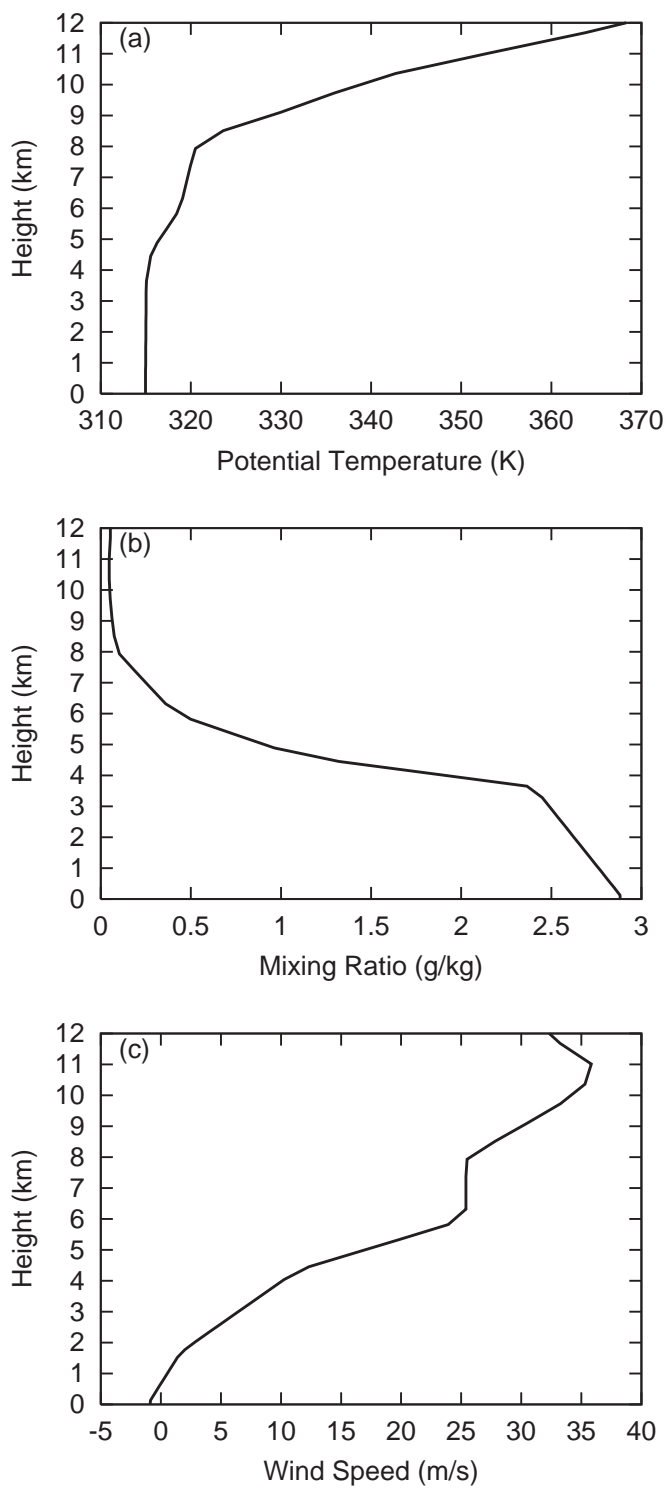

Fig. 1. Base-state vertical profiles of (a) potential temperature, (b) water vapor mixing ratio, and (c) wind speed (eastwest component).

the vertical (averaged in the $y$ direction) and horizontal cross sections of the simulated convective system at $6 \mathrm{~h}$ are shown. The cold-air pool which develops at the low levels advances at a fast speed of $22.7 \mathrm{~m} \mathrm{~s}^{-1}$ (relative to the stationary ground). At the leading edge of the cold pool, strong updrafts penetrating into the upper levels are seen, and in the upper layer the cloud region extends in both the forward
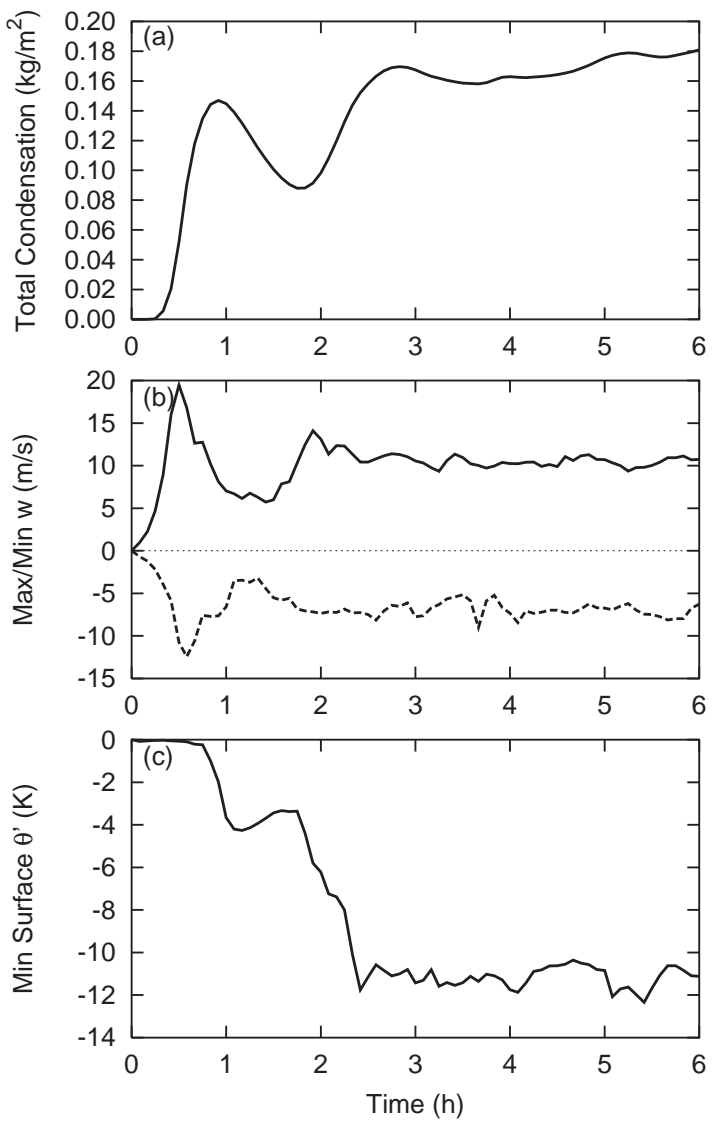

Fig. 2. Temporal variations of (a) areamean total condensation amount (i.e., water and ice content), (b) domainmaximum and -minimum vertical velocity, and (c) minimum surface potential temperature perturbation.

and rearward directions (Fig. 3). Note that the wind fiels shown in Fig. 3 are in a systemrelative sense (which means that the wind speed at the leading edge of the cold pool is zero) and the absolute wind speeds are obtained by adding $22.7 \mathrm{~m} \mathrm{~s}^{-1}$ to the systemrelative winds.

The system-relative wind field indicates a front-to-rear flow at middle levels above the cold pool and both forward and rearward flows at the upper levels. It is seen that eight convective cells align along the gust front (in the $y$ direction) of the convective system (Fig. 4), and thus each convective cell has a horizontal scale of about $15 \mathrm{~km}$ at this stage. All these features indicate that the simulated convective system 


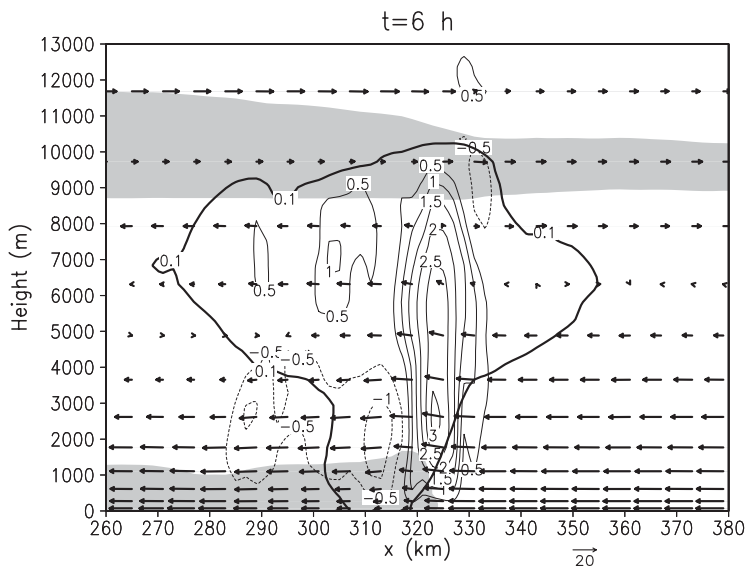

Fig. 3. Vertical cross section (averaged in the $y$ direction) of the simulated squall line at $6 \mathrm{~h}$. The horizontal axis indicates the exact location in the $x$ direction. Vertical velocity is contoured at the $0.5-\mathrm{m} \mathrm{s}^{-1}$ interval, system-relative wind vectors are depicted at every two grids, with the unit vector of $20 \mathrm{~m} \mathrm{~s}^{-1}$ shown in the lower right, a cloud boundary (i.e., total condensation mixing ratio of $0.1 \mathrm{~g} \mathrm{~kg}^{-1}$ ) is plotted by a single thick solid line, and the perturbation potential temperature of less than $-2 \mathrm{~K}$ is shaded.

has a structure of fast-moving, mid-latitude squall lines.

Considering that the simulated convective system at $6 \mathrm{~h}$ achieved a well-developed state as a squall line, we start the simulation initialized with the disturbance developed by the above-mentioned preliminary run at $6 \mathrm{~h}$ and this time we include the dust emission and transport computations in the time integration of the cloud model. As mentioned in Section 2.2, the dust flux at the surface occurs when the friction velocity exceeds the defined threshold value.

\section{Results}

\subsection{Evolution of squall line and dust transport}

Overall features of the simulated squall line and the associated dust transport are demonstrated first. As a measure of the convection development, the total condensation (i.e., water and ice phase) amount and the minimum sur-

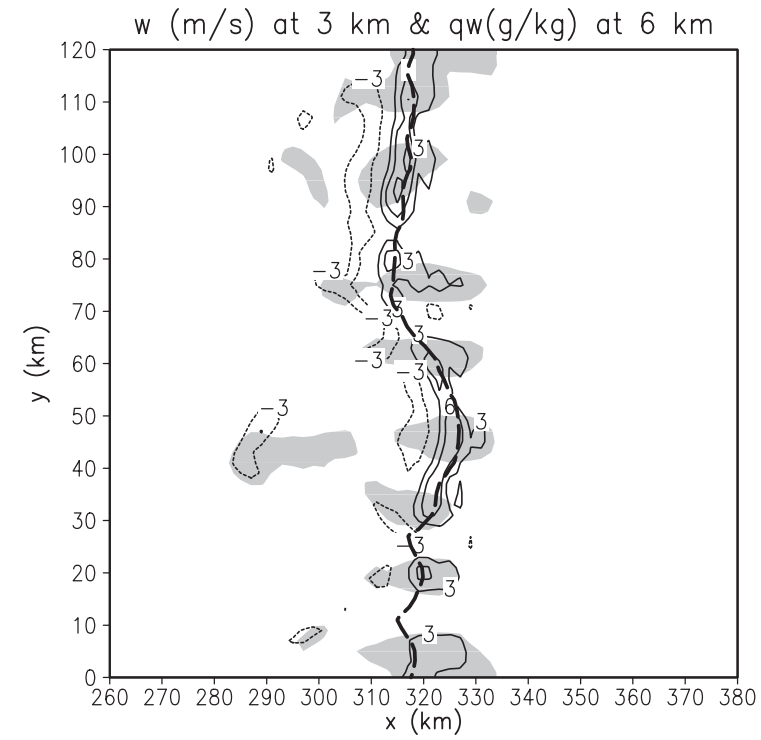

Fig. 4. Horizontal cross section of vertical velocity (contoured with the $3-\mathrm{m} \mathrm{s}^{-1}$ interval) at the $3-\mathrm{km}$ height and total water mixing ratio (shaded, greater than $1 \mathrm{~g} \mathrm{~kg}^{-1}$ ) at the $6-\mathrm{km}$ height at $6 \mathrm{~h}$. The position of the surface gust front is also plotted by a dashed line.

face potential temperature perturbation are examined here. Figure 5 shows the time evolution of these parameters, along with the maximum dust content in the computational domain for the case with the dust particle radius of $1 \mu \mathrm{m}$. In the present simulations, the content of wet-scavenged dust is explicitly predicted by (5), and thus the concentration of dust that is captured by rain water can also be plotted in Fig. 5c. The amount of total condensation is steadily increasing, and the surface cold pool maintains its strength. The maximum dust concentration varies around $150-240 \mathrm{mg} \mathrm{m}^{-3}$ after $7 \mathrm{~h}$ up to $12 \mathrm{~h}$, while the maximum concentration of rain-wet dust is at most $17 \mathrm{mg} \mathrm{m}^{-3}$, less than $10 \%$ of the transported dust content. A significantly strong cold pool develops at around $13 \mathrm{~h}$ (Fig. 5b); this cold pool induces severe surface winds, which results in a larger amount of surface emission of dust and a maximum dust content of $624 \mathrm{mg} \mathrm{m}^{-3}$ (Fig. 5c). It was reported in the 5 May 1993 event that the aerosol concentration in the air during the duststorm was up to $1016 \mathrm{mg} \mathrm{m}^{-3}$ (Mitsuta 

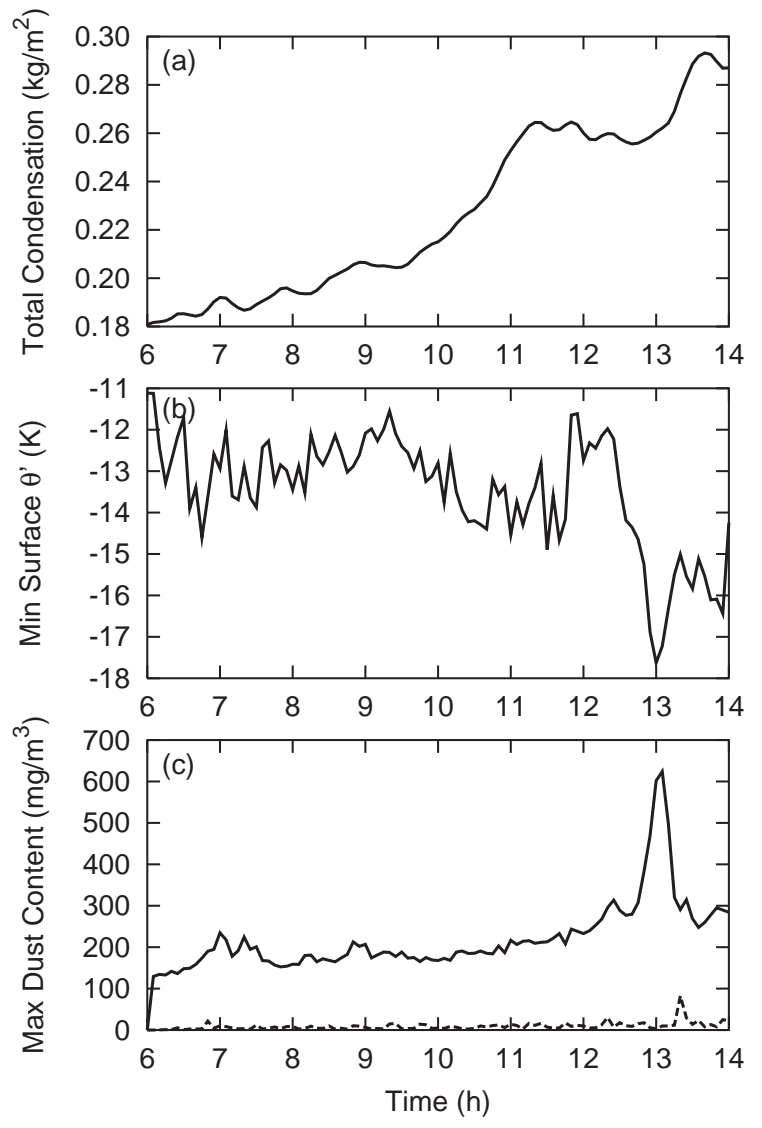

Fig. 5. Temporal variations of (a) areamean total condensation amount (i.e., water and ice content), (b) minimum surface potential temperature perturbation, and (c) domain-maximum dust concentration (solid) and rain-wet dust concentration (dashed) during 6 to $14 \mathrm{~h}$. The dust particle radius in this case is $1 \mu \mathrm{m}$.

et al. 1995). Comparing with this reported value, we consider that the present simulations successfully capture the observational feature of the duststorm in spite of a rather idealized experimental setup.

Figure 6 demonstrates the line-averaged $x-z$ views of the simulated squall line at $8,10,12$, and $14 \mathrm{~h}$. As time progresses, the cloud region at the upper levels extends horizontally relative to the location of the surface gust front, especially in the rearward direction, and the surface cold pool also spreads in its area, which indicates that the area of high surface winds and hence the amount of dust emission con-

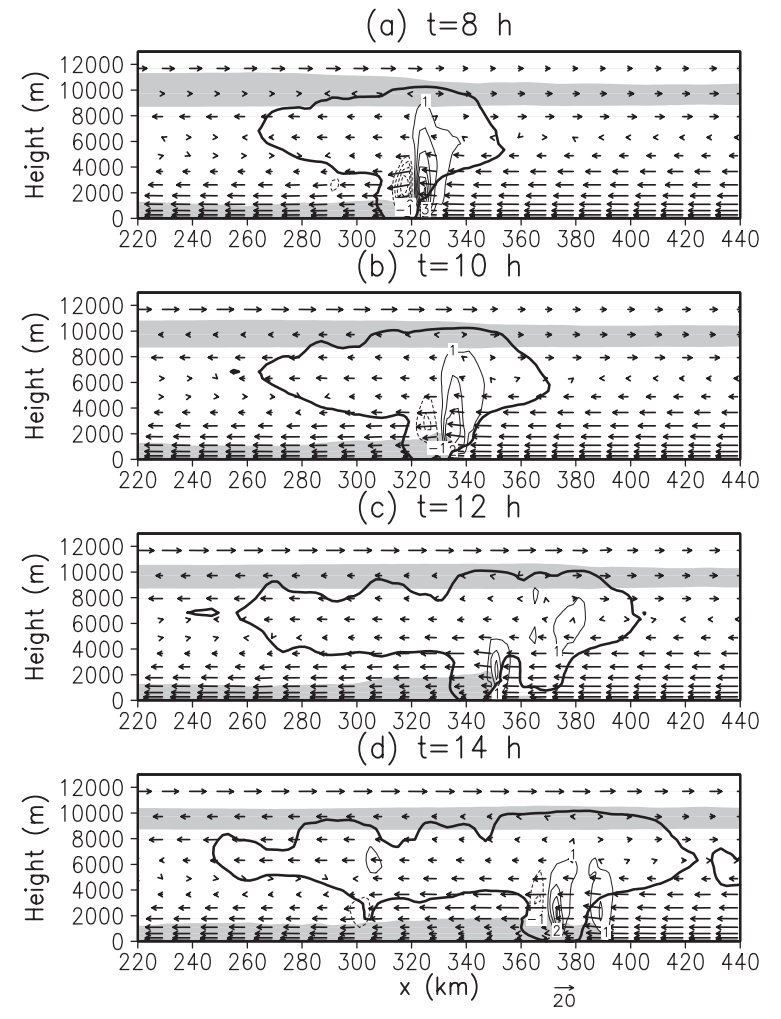

Fig. 6. The same as Fig. 3, except (a) at $8 \mathrm{~h},(\mathrm{~b})$ at $10 \mathrm{~h},(\mathrm{c})$ at $12 \mathrm{~h}$, and (d) at $14 \mathrm{~h}$ with the vertical velocity contoured at the $1-\mathrm{m} \mathrm{s}^{-1}$ interval.

tinuously increases. It appears that the updrafts at the leading edge of the cold pool become weaker and weaker at the later stages (Figs. 6b, c, and d); this is due to a large variability of the squall line (i.e., arc-shaped) in the along-line $(y)$ direction, which may result in the reduction of the intensities of the variables in a line-averaged perspective. Obviously, Fig. 5 indicates that the simulated squall line continuously grows and maintains its strength.

The evolution of the dust transport during the squall-line development is demonstrated in Figs. 7 and 8 for the cases with the dust radius of $1 \mu \mathrm{m}$ and $10 \mu \mathrm{m}$, respectively. It should be noted that the flux is shown in a systemrelative view. The areas of high dust concentration of greater than $10 \mathrm{mg} \mathrm{m}^{-3}$ are seen within the surface cold pools where a large amount of the surface dust flux is induced. The areas of moderate dust concentration of more than $0.1 \mathrm{mg} \mathrm{m}^{-3}$ are seen mainly in two areas: 
(a) $t=8 \mathrm{~h}$

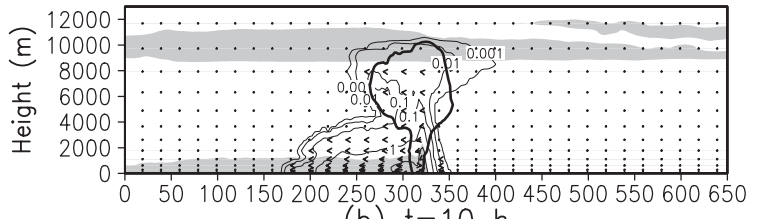

(b) $t=10 \mathrm{~h}$

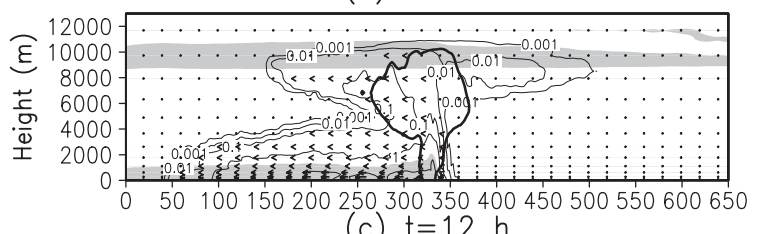

(c) $t=12 h$

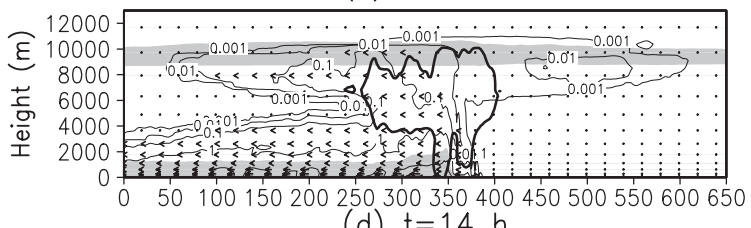

(d) $t=14 \mathrm{~h}$

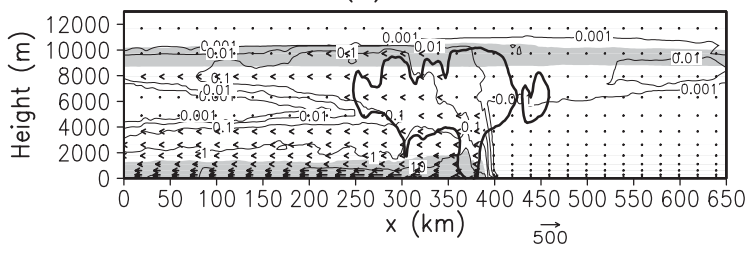

Fig. 7. Line-averaged vertical cross section of dust concentration (contoured at $0.001,0.01,0.1,1$, and $10 \mathrm{mg} \mathrm{m}^{-3}$ ), cloud boundary (a thick, solid contour, total condensation mixing ratio of $0.1 \mathrm{~g} \mathrm{~kg}^{-1}$ ), potential temperature perturbation (shaded, less than $-2 \mathrm{~K}$ ), system-relative mass flux of dust (vectors, the unit of $500 \mathrm{mg} \mathrm{m}^{-2} \mathrm{~s}^{-1}$ shown in the lower right) (a) at $8 \mathrm{~h}$, (b) at $10 \mathrm{~h}$, (c) at $12 \mathrm{~h}$, and (d) at $14 \mathrm{~h}$ for the case with the dust radius of $1 \mu \mathrm{m}$. The width shown corresponds to the whole computational $x$-domain.

one is the lowest 4-km layer behind the gust front, extending rearward with time; and the second is the upper levels within and rearward of the cloud regions. This second area is at first suppressed below the 6-km level (Figs. 7a and $8 \mathrm{a}$ ), and then penetrates into the upper layer and spreads rearward of the system in the later stages at 10,12 , and $14 \mathrm{~h}$. This transport feature seems to be closely related to the systemscale (or mesoscale) circulation within a squallline system, namely front-to-rear flow at middle to upper levels (e.g., Houze et al. 1989). During (a) $t=8 \mathrm{~h}$

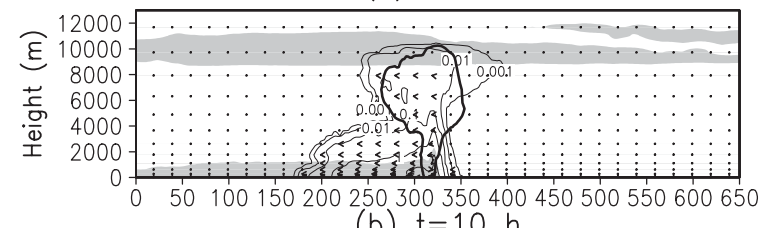

(b) $t=10 \mathrm{~h}$

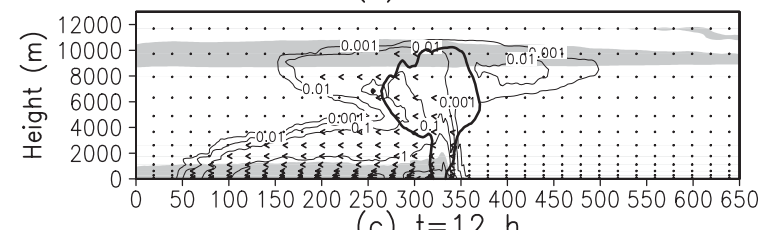

(c) $t=12 \mathrm{~h}$

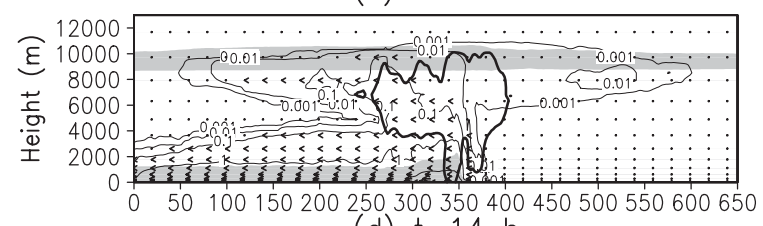

(d) $t=14 \mathrm{~h}$

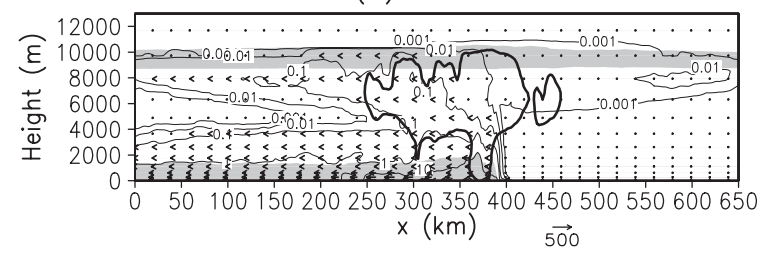

Fig. 8. The same as Fig. 7, except for the case with the dust radius of $10 \mu \mathrm{m}$.

the periods shown in Fig. 6, front-to-rear flow prevailed from the active convective regions out to the rear of the system in a system-relative sense. Similar to the cloud evolution found in Fig. 6, the area of dust concentration of greater than $0.001 \mathrm{mg} \mathrm{m}^{-3}$ in the upper layer gradually spreads both forward and rearward of the active convective center. There is a patch of dust enclosed by the $0.01-\mathrm{mg} \mathrm{m}^{-3}$ contour line in the upper layer ahead of the system, which moves forward. The movement of this area may be relevant to a gravity wave activity induced by the main convective core of the squall line (Nicholls et al. 1991), but this point is beyond the scope of the present study and thus we will not investigate it in detail.

No significant difference can be identified between the results obtained from the two different sizes of dust particle (Figs. 7 and 8). A slightly noticeable feature is that the area enclosed by a contour line in the $10-\mu \mathrm{m}$ size case shrinks a little more than in the $1-\mu \mathrm{m}$ size case. It should be noted that in the present simu- 
lations the total dust fluxes at the surface are identical between the $1-\mu \mathrm{m}$ size and $10-\mu \mathrm{m}$ size cases; dust flux in both cases is computed by (2). If the particle size distribution is taken into consideration, the flux of heavier dust will be smaller than the flux of lighter dust, and hence the total dust content floating in the upper layer would be reduced in the larger-particle cases.

A line-averaged analysis documented in this subsection provides an overall view of the dust transport from the surface to upper levels during the development and evolution of the squall line. In the following, the detailed dynamical processes relevant to the dust transport are examined.

\subsection{Convective-scale transport of dust}

From the results shown in Figs. 7 and 8, a substantial difference between the two cases was not identified. Therefore, the analyses will be focused on the case with the dust size of $1 \mu \mathrm{m}$ in this subsection.

Figure 9 shows the fields of the horizontal and vertical mass fluxes of dust at the surface and vertically averaged in layers of $0-1 \mathrm{~km}, 1-$ $3 \mathrm{~km}, 3-6 \mathrm{~km}$, and $6-10 \mathrm{~km}$ at $10 \mathrm{~h}$. The fluxes are defined as the product of dust mass and velocity, except for the surface dust flux which can be obtained with (2). In this figure, the fluxes below the $6-\mathrm{km}$ height are indicated in a ground-relative view, while those above the 6$\mathrm{km}$ height in a system-relative sense. The gustfront location averaged along the squall line at this time is at $334 \mathrm{~km}$. A large amount of the horizontal and vertical fluxes at the surface is seen just behind the gust front and extending rearward about $10-20 \mathrm{~km}$. In the lowest layer (Fig. 9b) the area of the large vertical flux appears to be concentrated and be aligned just behind the gust front. A large value of vertical flux can be identified as a linearly organized way also in the layer between $1-3 \mathrm{~km}$. The largest vertical flux in the $0-1 \mathrm{~km}$ layer reaches up to $80 \mathrm{mg} \mathrm{m} \mathrm{m}^{-2} \mathrm{~s}^{-1}$, which is about two times larger than that at the surface, and furthermore, the peak vertical flux in the 1$3 \mathrm{~km}$ layer is still larger than that at the surface. This implies that the dust emitted at the surface in the cold-pool region is advected by high winds within the cold pool and converges toward the leading edge of the cold pool, which then leads to a large vertical flux in the boundary layer by the mechanism described later in this subsection. Above the $3-\mathrm{km}$ level, the area of large vertical flux has a cellular feature, and the area of larger horizontal flux, rearward in a system-relative view, is found in the rear part of the cellular regions of large vertical flux (Figs. 9d, e). A weak forward flux ahead of the cold pool edge is found in the upper levels of 6$10 \mathrm{~km}$.

Along the line of active transport of dust found in Fig. 9, a $y-z$ cross section is demonstrated in Fig. 10 to examine the vertical structure of dust transport. In Fig. 10a, it can be seen that within the lowest layer below the 2 -km height are a couple of high dust concentration areas with the horizontal spacing of about $20 \mathrm{~km}$ (see the contour line of $10 \mathrm{mg} \mathrm{m}^{-3}$ ) and are a large variability in the $y$ components of fluxes. These high concentration areas seem to be extending upward and then to be advected in the $x$ direction (Fig. 10b). In Figs. 10c and 10d cloud and rain features are depicted. Within the atmospheric column with high dust concentration at low levels, welldeveloped cloud cells and rain cells are not seen (e.g., see the column at $y=40 \mathrm{~km}$ ); namely, dust is more actively transported upward in more cloud-free and/or rain-free areas. This seems to be reasonable, because in the regions of intense rain cells downward motion prevails and hence leads to less upward transport of dust.

At the location of $y=40 \mathrm{~km}$ where upward penetration of high dust concentration as well as large dust flux is clearly seen (Fig. 9), the time lapse of wind fields as well as cloud and dust development near the gust front is closely examined and is shown in Fig. 11. Initially a strong updraft is seen at the gust front at $10 \mathrm{~h}$ $0 \mathrm{~min}$; then the strong updraft region gradually extends upward at $10 \mathrm{~h} 5 \mathrm{~min}$ and $10 \mathrm{~min}$; and a cloud cell simultaneously develops. This type of cellular evolution is quite similar to that identified numerically for a mid-latitude squall line (e.g., Rotunno et al. 1988; Fovell and Tan 1998); in that case periodic cellular evolution controls the multi-cellular and long-lasting behavior of a squall-line system. In the present case, the cellular evolution seems to contribute to the upward and rearward spread in the area of high dust concentration. In Fig. 12, it is 
(a) Surface Dust Flux

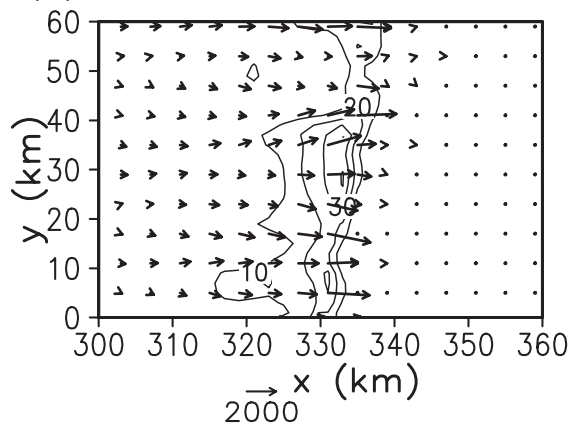

(c) Dust Flux at $1-3 \mathrm{~km}$

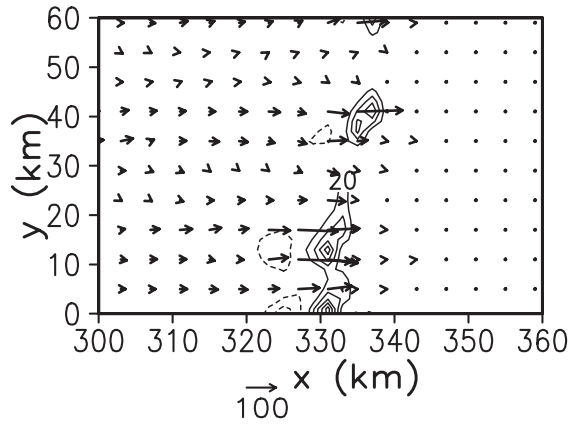

(e) Dust Flux at $6-10 \mathrm{~km}$

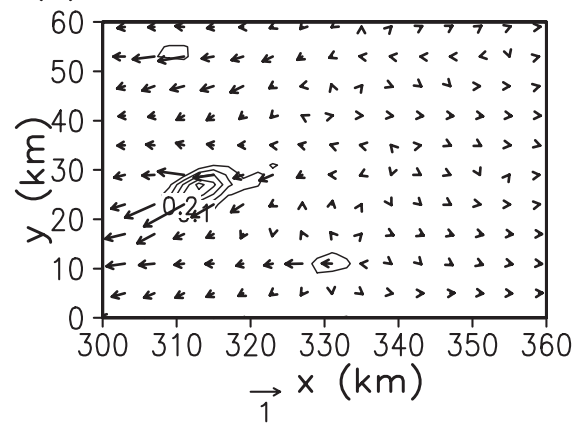

(b) Dust Flux at $0-1 \mathrm{~km}$

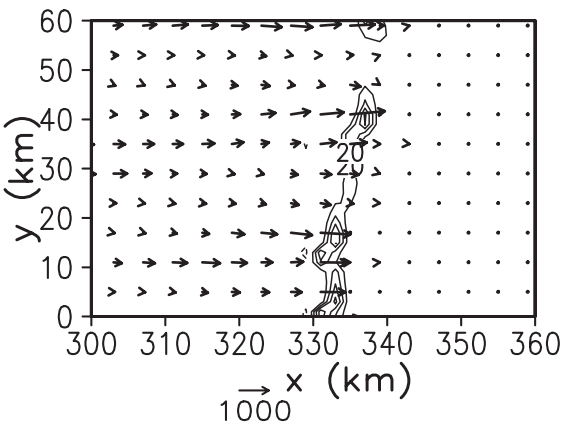

(d) Dust Flux at $3-6 \mathrm{~km}$

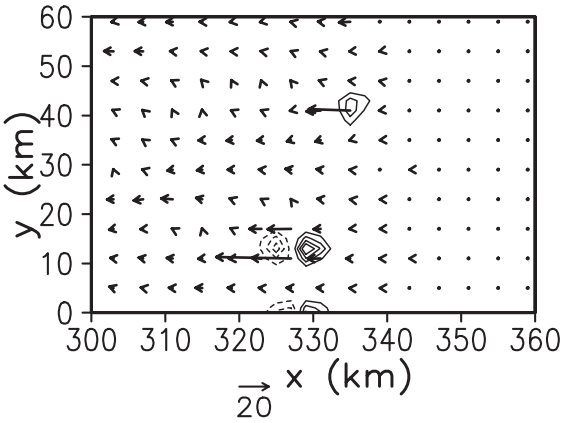

Fig. 9. Horizontal cross section of horizontal dust flux (vectors), and vertical dust flux (contoured) (a) at the surface, and vertically averaged in (b) the $0-1 \mathrm{~km}$ layer, (c) the 1-3 km, (d) the 3-6 km, and (e) the $6-10 \mathrm{~km}$ at $10 \mathrm{~h}$ for the case with the dust radius of $1 \mu \mathrm{m}$. The fluxes are indicated in a ground-relative sense in the panels (a), (b), and (c), and in a system-relative sense in the panels (d) and (e). The unit vectors (in $\mathrm{mg} \mathrm{m}^{-2} \mathrm{~s}^{-1}$ ) are shown in the bottom of each panel, and the contour intervals are $10 \mathrm{mg} \mathrm{m}^{-2} \mathrm{~s}^{-1}$ in the panel (a), 20 in (b) and (c), 3 in (d), and $0.1 \mathrm{in}(\mathrm{e})$.

shown that strong updrafts (and thus convective cells) are regenerated at the leading edge of the cold pool during the development of the squall-line system and high dust concentrations are found accompanied by the updraft development. Therefore, the cycle of the dust transport shown in Fig. 11 continuously takes place along the squall line. This regeneration of convective cells and the associated cycle of dust transport determines the system-scale feature of the dust transport demonstrated in Figs. 7 and 8 .

In Fig. 11 the highest concentration of dust is seen within the cold pool; the concentration contour of $10 \mathrm{mg} \mathrm{m}^{-3}$ is nearly identical with the cold-pool boundary. Dust emitted by coldpool-induced high winds at the surface seems to be at first mixed within the cold pool, which 
(a) Dust Flux \& Conc.

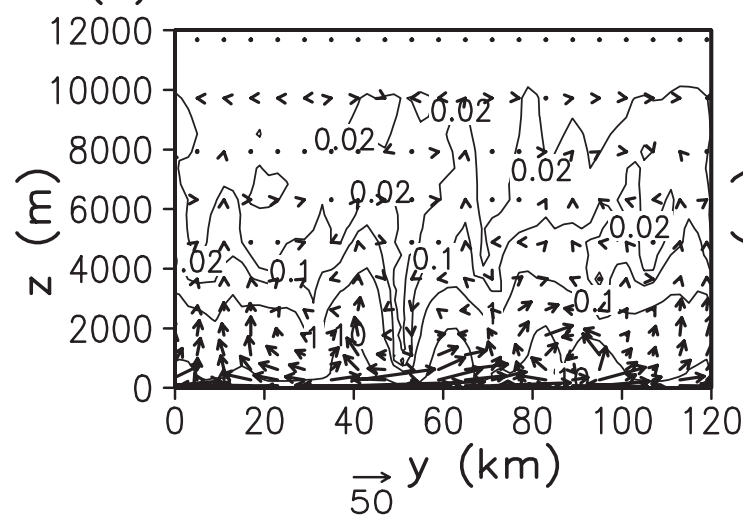

(c) Total Condensation

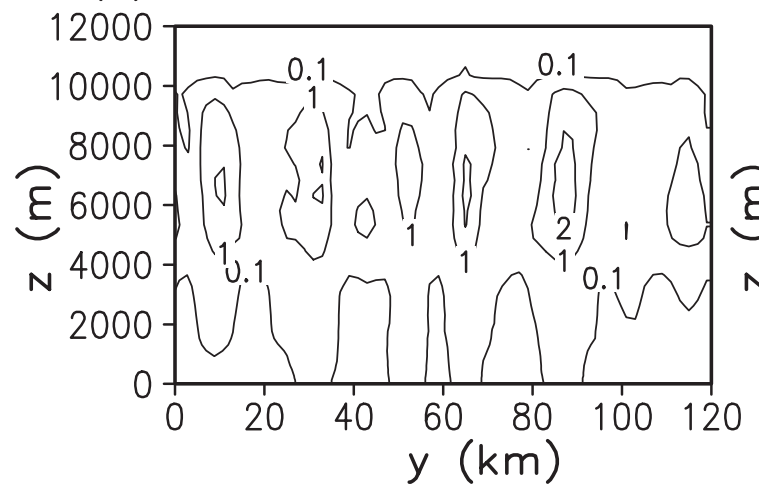

(b) Horizontal Dust Flux

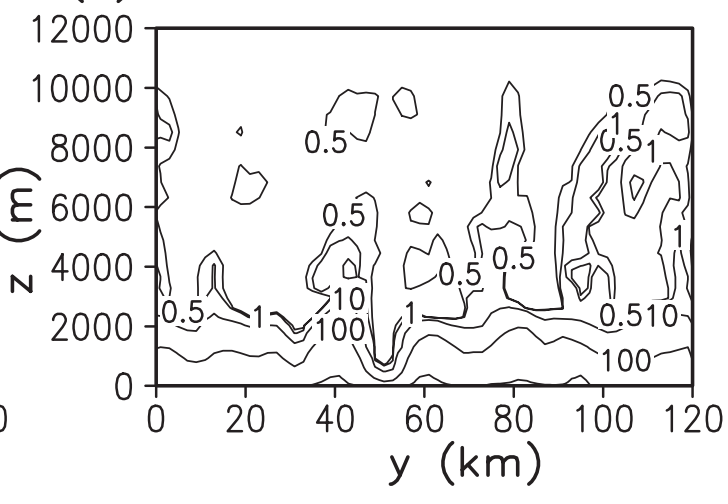

(d) Rain Water

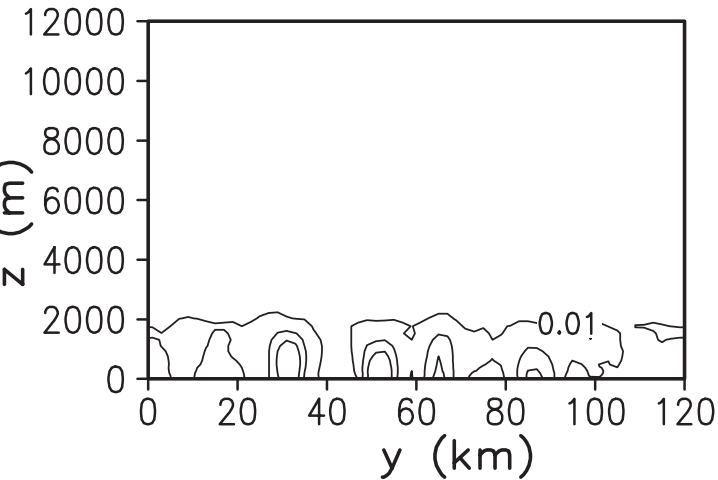

Fig. 10. $y-z$ cross section (averaged between $x=330 \mathrm{~km}$ and $340 \mathrm{~km}$ ) of (a) dust flux in the $y-z$ plane (vectors, with the unit in $\mathrm{mg} \mathrm{m}^{-2} \mathrm{~s}^{-1}$ shown in the bottom) and dust concentration (contoured at $0.02,0.1,1$, and $10 \mathrm{mg} \mathrm{m}^{-3}$ ), (b) ground-relative dust flux in the $x$ direction (contoured at $0.5,1,10$, 100 , and $1000 \mathrm{mg} \mathrm{m}^{-3}$ ), (c) total condensation mixing ratio (contoured at $0.1,1.0$, and $2.0 \mathrm{~g} \mathrm{~kg}^{-1}$ ), and (d) rain-water mixing ratio (contoured at $0.01,0.1$, and $0.2 \mathrm{~g} \mathrm{~kg}^{-1}$ ) at $10 \mathrm{~h}$ for the 1 - $\mu \mathrm{m}$-dust case.

can be regarded as a reservoir of dust. In this situation, the transfer of dust through the interface of cold pool will be crucial for the upward transport of dust by convective updrafts. In order to examine the mixing characteristics around the cold-pool boundary, the turbulence fields from the subgrid-mixing parameterization are examined in Fig. 13. It is clearly indicated that the turbulence intensity and the eddy viscosity coefficient are larger at and around the leading edge of the cold pool than within and ahead of the cold pool. This feature strongly suggests that active turbulent mixing at the leading edge of the cold pool plays a key role in transferring dust reserved in the cold pool out to updraft region and upper into the upper atmosphere.
In the foregoing we have argued the importance of the dynamical effects by cold pool on dust transport. We will here assess the amount of transported dust in various domains relative to the gust front position. Considering the dust transport feature shown in Fig. 7, we divide the whole computational domain, as shown in Fig. 14a, into the following: DOMAIN1, the domain behind the gust front in the layer between the 0-1 km level; DOMAIN2, behind the gust front in the layer of the $1-5 \mathrm{~km}$ levels; DOMAIN3, behind the gust front in the layer of the 5$10 \mathrm{~km}$ levels; and DOMAIN4, ahead of the gust front in the layer of the $5-10 \mathrm{~km}$ levels. Figures $14 \mathrm{~b}$ and $14 \mathrm{c}$ shows the temporal variation of the mean dust concentration in each defined domain for the cases with the dust radius of 
(a) $10 \mathrm{~h} 00 \mathrm{~min}$

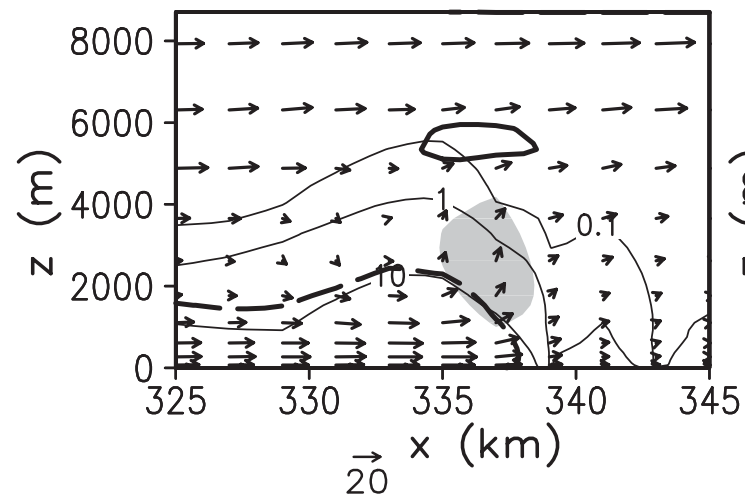

(c) $10 \mathrm{~h} 10 \mathrm{~min}$

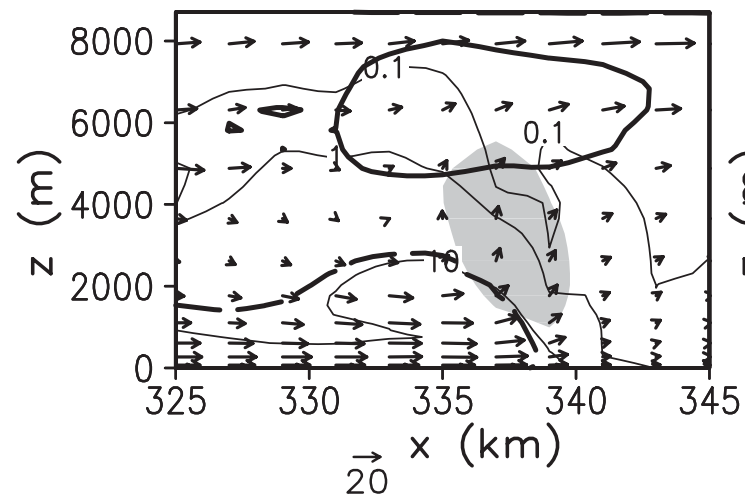

(b) $10 \mathrm{~h} 05 \mathrm{~min}$

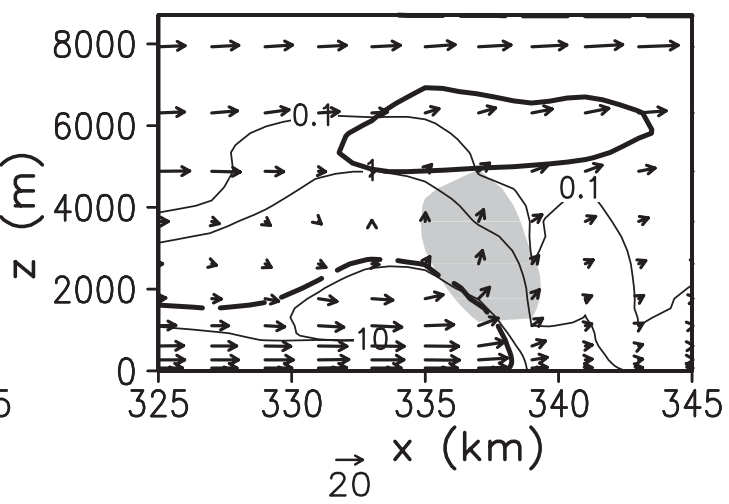

(d) $10 \mathrm{~h} 15 \mathrm{~min}$

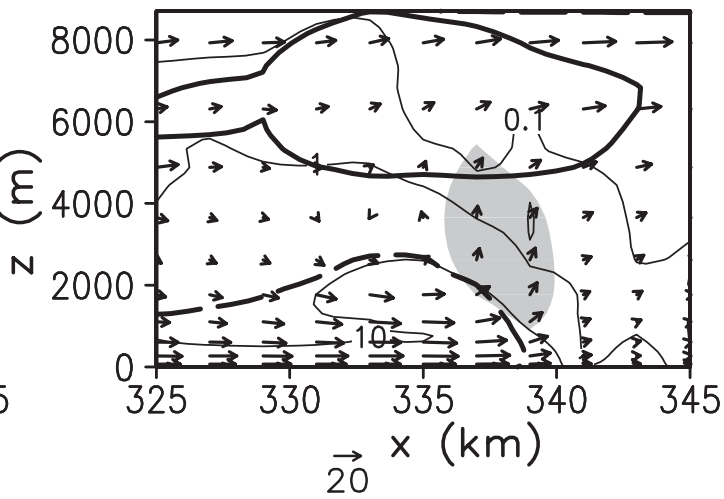

Fig. 11. $x-z$ cross section (averaged between $y=35 \mathrm{~km}$ and $45 \mathrm{~km}$ ) of dust concentration (contoured at $0.1,1.0$, and $10 \mathrm{mg} \mathrm{m}^{-3}$ ), potential temperature perturbation (-2 $\mathrm{K}$ contour with a thick, dashed line), total condensation mixing ratio $\left(1.0 \mathrm{~g} \mathrm{~kg}^{-1}\right.$ contour with a thick, solid line), strong updraft region (shaded, vertical velocity of greater than $6 \mathrm{~m} \mathrm{~s}^{-1}$ ), and wind vector (in $\mathrm{m} \mathrm{s}^{-1}$, the unit shown in the bottom of each panel) (a) at $10 \mathrm{~h}$, (b) at $10 \mathrm{~h} 5 \mathrm{~min}$, (c) at $10 \mathrm{~h} 10 \mathrm{~min}$, and (d) at $10 \mathrm{~h}$ $15 \mathrm{~min}$.

$1 \mu \mathrm{m}$ and $10 \mu \mathrm{m}$. The dust concentrations in all the domains steadily increase as the dust is continuously supplied from the ground. The mean concentration diminishes by an order of magnitude as the domain goes from DOMAIN1 to DOMAIN2, DOMAIN3, and further to DOMAIN4. Within the cold pool region (DOMAIN1) the concentrations for the $1-\mu \mathrm{m}$ and $10-\mu \mathrm{m}$ cases reach as high as $15.2 \mathrm{mg} \mathrm{m}^{-3}$ and $10.6 \mathrm{mg} \mathrm{m}^{-3}$ respectively at $14 \mathrm{~h}$. Behind the gust front, the mean concentration in the 1$5 \mathrm{~km}$ levels are still above $1 \mathrm{mg} \mathrm{m}^{-3}$. There is a significant difference between the mean dust concentrations ahead of and behind the gust front in the upper layer of $5-10 \mathrm{~km}$ : about
$0.1 \mathrm{mg} \mathrm{m}^{-3}$ in DOMAIN3; and less than $0.005 \mathrm{mg} \mathrm{m}^{-3}$ in DOMAIN4.

In this way, the amount of transported dust significantly differs not only in the boundary layer but also in the upper atmosphere depending on the region relative to the gust front, and thus seems to be significantly controlled by the dynamical effects of the surface cold pool. This behavior can be interpreted by the reasoning of Rotunno et al. (1988); as the cold pool intensifies, the updraft is then tilted rearward and hence the front-to-rear flow prevails at middle to upper levels from a system-scale viewpoint, which will result in more active transport of dust in the upper-rear part of the system. 


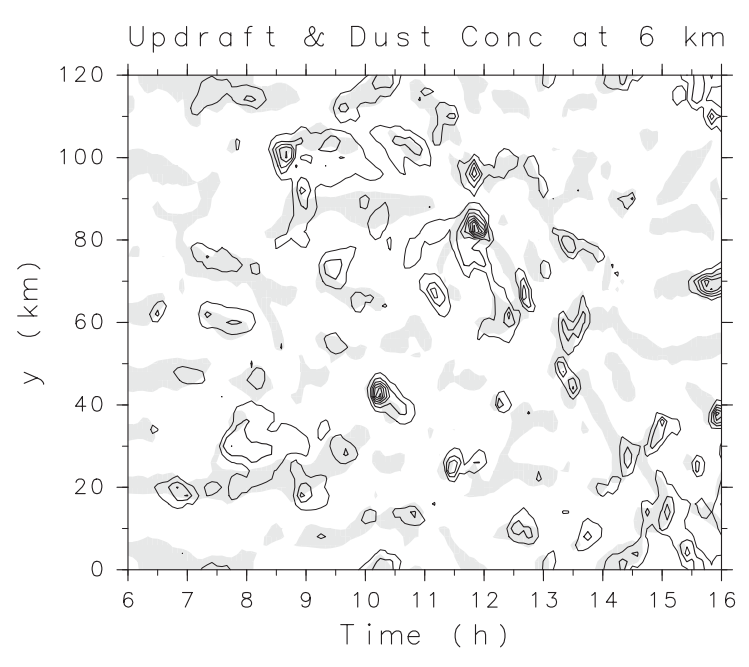

Fig. 12. Time-spatial (in the $y$ direction) diagram of updraft and dust concentration at the $6-\mathrm{km}$ level, averaged in the $x$ direction between 5 - $\mathrm{km}$-ahead of and -behind the locations of surface gust front. The updrafts over $3 \mathrm{~m} \mathrm{~s}^{-1}$ are shaded, and the dust concentrations are contoured at every $0.05 \mathrm{mg} \mathrm{m}^{-3}$.

\section{Summary and conclusions}

Three-dimensional cloud-resolving simulations (with the horizontal resolution of $2 \mathrm{~km}$ ) coupled with a dust emission/transport model were performed in order to explicitly represent convective- and cloud-scale processes such as updraft/downdraft, surface cold pool, precipitation, and cloud microphysics and thereby to describe the convective dynamics for dust emission and transport from a cloud-scale to a mesoscale perspective. The case of the 5 May 1993 duststorm over the Gobi Desert, which was caused by a squall-line-type mesoscale convective system (Takemi 1999b), was examined in this study, and the model was set up in an idealized fashion to better concentrate on the primary mechanisms for convectivescale dust transport within a squall-line-type convective system. In modeling the dust emission and transport processes, we followed a standard approach from the previous dust modeling studies, implementing an additional equation for wet-scavenged dust. Owing to the computer resources available and in addition to some uncertainties which may obscure the central focus of this study, we assumed the dust

\section{(a) Turbulent Kinetic Energy}

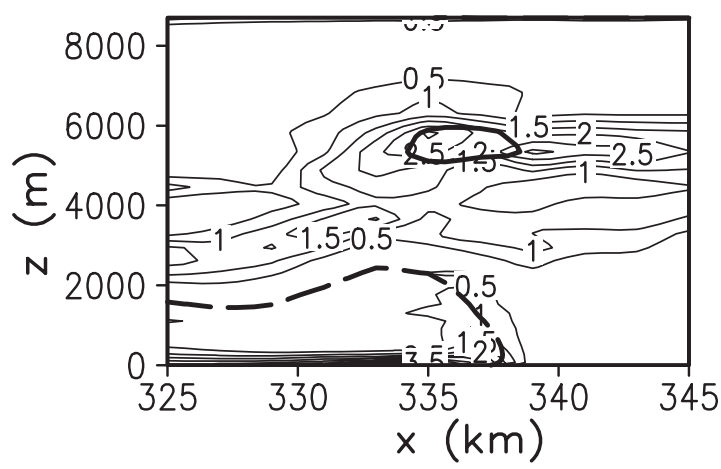

(b) Eddy Viscosity (Vertical)

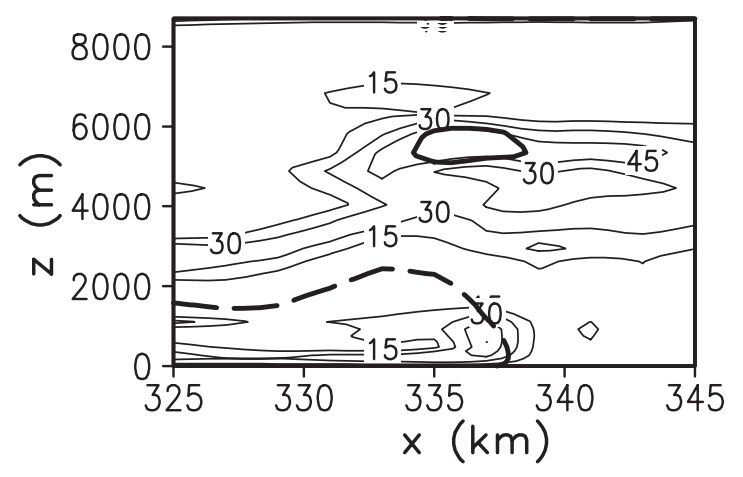

Fig. 13. $x-z$ cross section (averaged between $y=35 \mathrm{~km}$ and $45 \mathrm{~km}$ ) of potential temperature perturbation ( $-2 \mathrm{~K}$ contour with a thick, dashed line) and total condensation mixing ratio (1.0 $\mathrm{g} \mathrm{kg}^{-1}$ contour with a thick, solid line), along with (a) turbulent kinetic energy (contoured at every $0.5 \mathrm{~m}^{2} \mathrm{~s}^{-2}$ ) and ( $b$ ) eddy viscosity coefficient in the vertical (contoured at every $15 \mathrm{~m}^{2} \mathrm{~s}^{-1}$ ). The vertical cross section at $10 \mathrm{~h}$ is shown.

particle as a single-sized one. Although the simulations are configured in the idealized settings, the maximum dust concentration reached as high as $624 \mathrm{mg} \mathrm{m}^{-3}$ which is in fair agreement with the reported value during the observed event $\left(1016 \mathrm{mg} \mathrm{m}{ }^{-3}\right.$, Mitsuta et al. 1995); this makes the results and analyses of the present idealized simulations more reasonable.

Dust, once emitted at the surface, is transported upward in the lower atmosphere by convective-scale updraft which is forced con- 
(a) DOMAIN DEFINITION

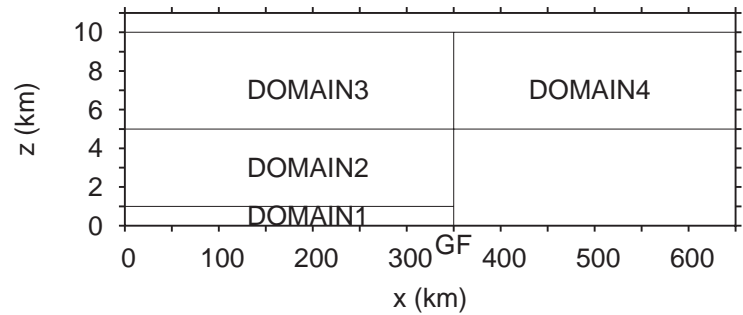

(b) Dust Particle Radius : $1 \mu$

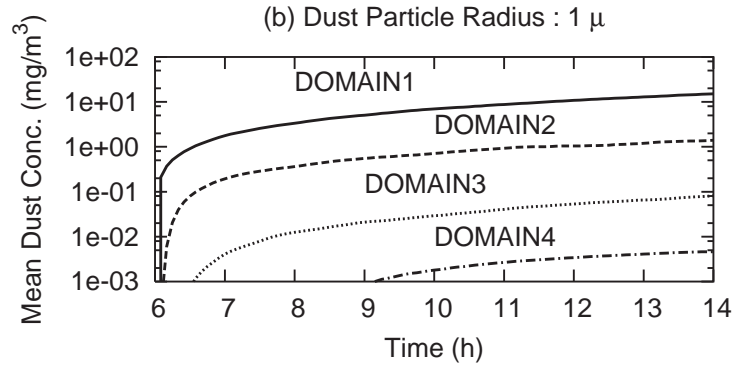

(c) Dust Particle Radius : $10 \mu$

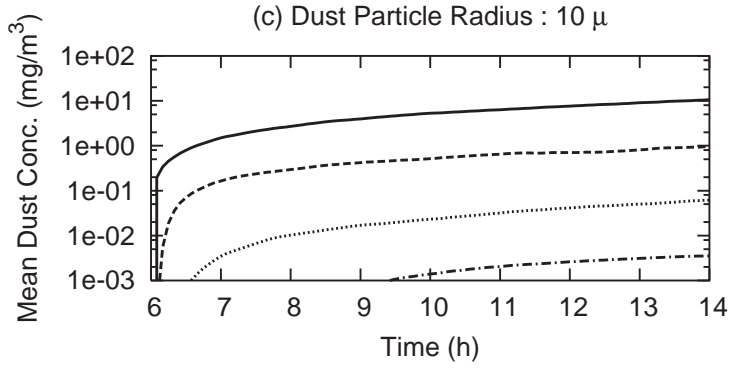

Fig. 14. (a) Definition of the domains for the calculation of averaged dust concentration, and temporal variations of domain-averaged dust concentration (in $\mathrm{mg} \mathrm{m}^{-3}$ ) for the cases with the dust particle radius of (b) $1 \mu \mathrm{m}$ and (c) $10 \mu \mathrm{m}$. GF in (a) denotes the position of the surface gust front.

tinuously at the leading edge of the squall-line cold pool, and then spreads laterally in the cross-line directions at upper levels by systemscale circulation within the squall line. In the upper layer the rearward transport of dust is more pronounced than the forward transport, owing mainly to the front-to-rear flow which can be typically found in the squall-line convective systems.

The surface winds are the strongest within the cold-pool region, and as a result a high dust concentration is found and mixed within the cold pool. In other words, cold pool can be re- garded as a reservoir of dust. In order for the dust contained in the cold pool to be entrained in the convective updraft, the mechanisms for the transfer of the contained dust out of the cold pool will then be crucial. The analysis of the subgrid-turbulence characteristics at and around the cold-pool boundary indicates that the turbulent mixing at the leading edge of the cold pool plays a key role in transferring dust out of the cold pool. After transferred into the updraft region out of the cold pool, dust will be transported into the upper atmosphere. This process of the convective-scale dust transport continuously occurs along the leading edge of the cold pool through the regeneration of convective cells along the line during the convective-system evolution.

The amount of the transported dust from a system-scale perspective significantly depends on the domain relative to the location of the gust front. The upper-level mean dust concentration is by more than an order of magnitude larger in the rear part of the system than in the forward part of the system.

As the cold pool intensifies the forced updraft at the gust front will be tilted rearward and front-to-rear flow prevails at mid-to-upper levels. Associated with this squall-line circulation, a route of dust transport from the gust front to the upper rear of the system is thus established. It is concluded that the turbulent mixing and forced updraft at the leading edge of the squall-line cold pool and the intensity of the cold pool itself primarily determine and control the convective-scale as well as systemscale characteristics of dust transport.

The present study has dealt specifically with the squall-line case. The same argument presented here can also be applied to dust transport processes associated with synopticscale cold-frontal rainbands, since they show a similar structure with the squall-line system: namely, linear convective structure; deep convection development along the rainband; and a significant temperature gradient (frontal structure) at the surface. These elements may act cooperatively with each other in transporting dust from a convective-scale perspective. Therefore, it is suggested that the representations of convective-scale vertical transport processes should be adequately updated in order to improve the accuracy of the regional- 
scale to global-scale numerical predictions with grid spacings insufficient to resolve convective motions.

This study employed a horizontal grid spacing of $2 \mathrm{~km}$, which is assumed to be sufficient for cloud-resolving simulations, and revealed the basic mechanisms for convective dust transport. However, there are a number of issues to be resolved in a future work. For example, we stressed the importance of turbulent mixing at the interface of the cold pool and the pre-front environment. As can be seen in many dust front pictures (e.g., Fig. 2 of Mitsuta et al. 1995), the frontal surface indicates a highly turbulent structure. In order to quantitatively evaluate the amount of dust transfer, a veryhigh-resolution simulation that is capable of representing more detailed structures of the cold-pool edge may be required. In addition, we assumed in this study that the subgridturbulent mixing coefficient for dust content is the same with that for other scalar variables such as potential temperature and moisture content. The issue of the subgrid mixing parameterization for dust content should also be tackled in the near future.

\section{Acknowledgments}

The advice from Akira Yamamoto at Meteorological Research Institute, Japan Meteorological Agency on dust-emission modeling is greatly appreciated. The comments of the two anonymous reviewers are also acknowledged for improving the original manuscript. I would like to thank Ms. Reiko Watanabe for correcting English expressions in the original manuscript. This research was made as a part of the ADEC Project (Aeolian Dust Experiment on the Climate Impact) supported by the Special Coordination Fund for Promoting Science and Technology from the Ministry of Education, Culture, Sports, Science, and Technology (MEXT) of Japan. The ARPS model was developed by the Center for Analysis and Prediction of Storms (CAPS), The University of Oklahoma. CAPS is supported by the National Science Foundation and the Federal Aviation Administration through combined grant ATM92-20009.

\section{References}

Businger, J.A., J.C. Wyngaard, Y. Izumi, and E.F. Bradley, 1971: Flux-profile relationships in the atmospheric surface layer. J. Atmos. Sci., 28, 181-189.

Chen, S.J., Y.H. Kuo, P.Z. Zhang, and Q.F. Bai, 1991: Synoptic climatology of cyclogenesis over east Asia, 1958-1987. Mon. Wea. Rev., 119, 14071418.

d'Almeida, G.A. and L. Schutz, 1983: Number, mass and volume distributions of mineral aerosol and soils of the Sahara. J. Clim. Appl. Meteor., 22, 233-243.

Deardorff, J.W., 1980: Stratocumulus-capped mixed layers derived from a three-dimensional model. Bound.-Layer Meteor., 18, 495-527.

Durran, D.R. and J.B. Klemp, 1983: The effects of moisture on trapped mountain lee waves. $J$. Atmos. Sci., 39, 2152-2158.

Fovell, R.G. and P.-H. Tan, 1998: The temporal behavior of numerically simulated multicell-type storms. Part II: The convective cell life cycle and cell regeneration. Mon. Wea. Rev., 126, 551-577.

Gamo, M., 1996: Thickness of the dry convection and large-scale subsidence above deserts. Bound. -Layer Meteor., 79, 265-278.

Gillette, D.A. and R. Passi, 1988: Modeling dust emission caused by wind erosion. J. Geophys. Res., 93, 14233-14242.

Giorgi, F. and W.L. Chameides, 1986: Rainout lifetimes of highly soluble aerosols and gases as inferred from simulations with a general circulation model. J. Geophys. Res., 91, 1436714376.

Gong, S.L., L.A. Barrie, J.-P. Blanchet, K. von Salzen, U. Lohmann, G. Lesins, L. Spacek, L.M. Zhang, E. Girard, H. Lin, R. Leaitch, H. Leighton, P. Chylek, and P. Huang, 2003: Canadian aerosol module: a size-segregated simulation of atmospheric aerosol processes for climate and air quality models. 1. Module development. J. Geophys. Res., 108, 4007, doi:10.1029/2001JD002002.

Houze, R.A., Jr., S.A. Rutledge, M.I. Biggerstaff, and B.F. Smull, 1989: Interpretation of doppler weather radar displays of midlatitude mesoscale convective system. Bull. Amer. Meteor. Soc., 70, 608-619.

In, H.-J. and S.-U. Park, 2002: A simulation of longrange transport of yellow sand observed in April 1998 in Korea. Atmos. Environ., 36, 4173-4187.

Klemp, J.B. and R.B. Wilhelmson, 1978: The simulation of three-dimensional convective storm dynamics. J. Atmos. Sci., 35, 1070-1096.

Lin, Y.L., R.D. Farley, and H.D. Orville, 1983: Bulk parameterization of the snow field in a cloud model. J. Clim. Appl. Meteor., 22, 10651092. 
Liu, M. and D.L. Westphal, 2001: A study of the sensitivity of simulated mineral dust production to model resolution. J. Geophys. Res., 106, 18099-18112. , — S. Wang, A. Shimizu, N. Sugimoto, J. Zhou, and Y. Chen, 2003: A high-resolution numerical study of the Asian dust storms of April 2001. J. Geophys. Res., 108, 8653, doi:10.1029/2002JD003178.

Mahrt, L., 1976: Mixed layer moisture structure. Mon. Wea. Rev., 104, 1403-1407.

Mitsuta, Y., T. Hayashi, T. Takemi, Y. Hu, J. Wang, and M. Chen, 1995: Two severe local storms as observed in the arid area of northwest China. J. Meteor. Soc. Japan, 73, 1269-1284.

Nicholls, M.E., R.A. Pielke, and W.R. Cotton, 1991: Thermally forced gravity waves in an atmosphere at rest. J. Atmos. Sci., 48, 1869-1884.

Nickling, W.G. and J.A. Gillies, 1993: Dust emission and transport in Mali, West Africa. Sedimentology, 40, 859-868.

Parungo, F., Z. Li, X. Li, D. Yang, and J. Harris, 1994: Gobi dust storms and The Great Green Wall. Geophys. Res. Lett., 21, 999-1001.

Qian, W., L. Quan, and S. Shi, 2002: Variations of the dust storm in China and its climatic control. J. Climate, 15, 1216-1229.

Rotunno, R., J.B. Klemp, and M.L. Weisman, 1988: A theory for strong, long-lived squall lines. J. Atmos. Sci., 45, 463-485.

Seinfeld, J.H., G.R. Carmichael, R. Arimoto, W.C. Conant, F.J. Brechtel, T.S. Bates, T.A. Cahill, A.D. Clarke, S.J. Doherty, P.J. Flatau, B.J. Huebert, J. Kim, K.M. Markowicz, P.K. Quinn, L.M. Russell, P.B. Russell, A. Shimizu, Y. Shinozuka, C.H. Song, Y. Tang, I. Uno, A.M. Vogelmann, R.J. Weber, J.-H. Woo, and X.Y. Zhang, 2004: ACE-ASIA Regional climatic and atmospheric chemical effects of Asian dust and pollution. Bull. Amer. Meteor. Soc., 85, 367380.

Shao, Y., E. Jung, and L.M. Leslie, 2002: Numerical prediction of northeast Asian dust storms using an integrated wind erosion modeling system. J. Geophys. Res., 107, 4814, doi:10.1029/ 2001JD001493.

- , 2000: Physics and Modelling of Wind Erosion. Kluwer Academic Publishers, 393 pp.

Sun, W.-Y. and C.-Z. Chang, 1986: Diffusion model for a convective layer. Part I: Numerical simulation of convective boundary layer. J. Climate Appl. Meteor., 25, 1445-1453.

Takemi, T., 1999a: Evaporation of rain falling below a cloud base through a deep dry atmospheric boundary layer over an arid region. J. Meteor. Soc. Japan, 77, 387-397.

, 1999b: Structure and evolution of a severe squall line over the arid region in northwest China. Mon. Wea. Rev., 127, 1301-1309.

and T. Satomura, 2000: Numerical experiments on the mechanisms for the development and maintenance of long-lived squall lines in dry environments. J. Atmos. Sci., 57, 1718-1740.

- and N. Seino, 2005a: Duststorms and cyclone tracks over the arid regions in East Asia in spring. J. Geophys. Res., 110, D18S11, doi:10.1029/2004JD004698.

and N. Seino, 2005b: Duststorms and mesoscale cloud systems over the East Asian Deserts in spring. Water, Air, \& Soil Pollution, accepted.

Takemura, T., H. Okamoto, Y. Maruyama, A. Numaguti, A. Higurashi, and T. Nakajima, 2000: Global three-dimensional simulation of aerosol optical thickness distribution of various origins. J. Geophys. Res., 105, 17853-17873.

Uno, I., G.R. Carmichael, D.G. Streets, Y. Tang, J.J. Yienger, S. Satake, Z. Wang, J.-H. Woo, S. Guttikunda, M. Uematsu, K. Matsumoto, H. Tanimoto, K. Yoshioka, and T. Iida, 2003: Regional chemical weather forecasting system CFORS: Model descriptions and analysis of surface observations at Japanese island stations during the ACE-Asia experiment. J. Geophys. Res., 108, 8668, doi:10.1029/ 2002JD002845.

—, H. Amano, S. Emori, K. Kinoshita, I. Matsui, and N. Sugimoto, 2001: Trans-Pacific yellow sand transport observed in April 1998: A numerical study. J. Geophys. Res., 106, 1833118344.

Weisman, M. and R. Rotunno, 2004: "A theory for strong long-lived squall lines" revisited. $J$. Atoms. Sci., 61, 361-382.

, J.B. Klemp, and W.C. Skamarock, 1997: The resolution dependence of explicitly modeled convective systems. Mon. Wea. Rev., 125, 527-548.

Westphal, D.L., O.B. Toon, and T.N. Carlson, 1988: A case study of mobilization and transport of Saharan dust. J. Atmos. Sci., 45, 2145-2175.

Xue, M., K.K. Droegemeier, and V. Wong, 2000: The Advanced Regional Prediction System (ARPS) - A multiscale nonhydrostatic atmospheric simulation and prediction tool. Part I: Model dynamics and verification. Meteor. Atmos. Physics., 75, 161-193.

, -, A. Shapiro, K. Brewster, F. Carr, D. Weber, Y. Liu, and D.-H. Wang, 2001: The Advanced Regional Prediction System (ARPS)-A multiscale nonhydrostatic atmospheric simulation and prediction tool. Part II: Model physics and applications. Meteor. Atmos. Physics., 76, 134-165. 